\title{
Exercise limitation in juvenile onset Mixed Connective Tissue Disease (MCTD)
}

\author{
JJ van der Net, A van Royen-Kerkhof*, T Takken and B Wissink
}

Address: Wilhelmina Children's Hospital of the University Medical Center Utrecht, Utrecht, Netherlands

* Corresponding author

from $15^{\text {th }}$ Paediatric Rheumatology European Society (PreS) Congress

London, UK. 14-17 September 2008

Published: 15 September 2008

Pediatric Rheumatology 2008, 6(Suppl I):PI62 doi:I0.II86/I546-0096-6-SI-PI62

This abstract is available from: http://www.ped-rheum.com/content/6/SI/PI62

(c) 2008 Net et al; licensee BioMed Central Ltd.

\section{Objectives}

To study the impact of musculoskeletal and cardiorespiratory impairment on the exercise capacity in children with mixed connective tissue disease (MCTD). Frequently reported clinical symptoms include arthritis, myositis, fatigue and cardiorespiratory impairment. However, the exercise capacity of patients with MCTD has not been studied systematically before.

\section{Methods}

Eleven children diagnosed with MCTD (age 11-19) were studied in this retrospective chart review. Maximal exercise testing was used to determine the peak oxygen uptake $\left(\mathrm{VO}_{2 \text { peak }}\right)$ of the patients and a hand-held dynamometer was used to measure muscle strength. Cardiopulmonary function tests were used to measure obstructive or restrictive pulmonary impairment or cardiac failure.

\section{Results}

$\mathrm{VO}_{2 \text { peak }}$ was significantly lower in patients with MCTD compared to the $\mathrm{VO}_{2 \text { peak }}$ of healthy subjects (z-score -1.9, $\mathrm{p}=0.008$ ). The strength of the proximal muscles (hip flexors, shoulder abductors, knee extensors) of the patients was significantly lower than the controls, whereas the strength of the distal muscles (dorsal flexors of the foot and grip strength) was rather similar. No clinical relevant cardiopulmonary impairment was observed.

\section{Conclusion}

The exercise capacity, as well as proximal muscle strength is impaired in children with MCTD and differs significantly from healthy subjects. Since pulmonary problems were non dominant in this patient group, the decreased exercise capacity seems to be due to impairment of the musculoskeletal system. 